\title{
Is the Meaning of the "Sharing Economy" Shared Among Us? Comparing the Perspectives of Japanese and Swedish Policymakers and Politicians
}

\author{
Per Fors $^{1}$ (D) $\cdot$ Yu Inutsuka ${ }^{2} \cdot$ Takashi Majima $^{3} \cdot$ Yohko Orito $^{4}$
}

Received: 5 October 2020 / Accepted: 7 February 2021 / Published online: 28 February 2021

(c) The Author(s) 2021

\begin{abstract}
In another paper in this special issue, we explored how the sharing economy was understood and promoted by researchers in Japan and Sweden, respectively. In this second paper, which is based on two separate archival studies, we proceed by focusing on how the concept is used and understood in the political sphere by politicians and policymakers in the two contexts. On a general level, the sharing economy is understood as an economic model based on the acquisition, provision, and sharing of goods and services, facilitated by digital platforms. This study concludes that within the political spheres in Japan and Sweden there are, however, many different more specific understandings of and assumptions related to the concept. For example, the sharing economy is primarily promoted as a tool for economic revitalization and growth in Japan, while in Sweden its environmental benefits are emphasized. In Japan, there seems to be more consensus around what the sharing economy is, what its main effects are, and how it should be promoted. In Sweden, political parties instead advance different understandings of, and assumptions related to, the sharing economy to advance their political agendas. While the concept has been successfully translated in Japan by powerful political institutions and actors, we argue that the concept remains open to many different interpretations in Sweden.
\end{abstract}

Keywords Sharing economy · Collaborative consumption · Comparative study · Translation $\cdot$ Floating signifier

\section{Introduction}

Throughout the past decade, the sharing economy has become a popular phenomenon and buzzword in research, practice, and policy. The term is generally used interchangeably with collaborative consumption [1] and is an umbrella term for

Per Fors

Per.Fors@angstrom.uu.se

Extended author information available on the last page of the article 
peer-to-peer exchange of under-utilized assets [2]. While such practices have existed for a long time-indeed, since the dawn of human societies and settlements-what makes the sharing economy unique is that these practices are now facilitated by online digital platforms [3]. On such platforms, owners of assets (e.g. cars, homes, tools) can make their assets available for others to use, either for free or for a fee. A typical example of a sharing economy platform is Airbnb, where individuals and firms rent out apartments short-term, for a fee [4]. Ride sharing is another popular category in the sharing economy. Zipcar, ${ }^{1}$ Sunfleet $^{2}$ and Skjutsgruppen ${ }^{3}$ are examples of companies and non-profit organizations that facilitate ride sharing by making better use of under-utilized cars.

Although sharing economy actors are often praised for their innovativeness, growth, and contribution to social and environmental sustainability, critical voices highlight the negative effects of these kinds of practices and business models. Researchers have recently argued that while there is potential for the sharing economy to contribute to sustainable development, numerous rebound effects ought to be considered. For example, cheaper accommodations abroad allow people to spend more money travelling, which increases emissions [5]. As renting is cheaper than buying, people who save money through the use of sharing economy platforms have more money to spend on other, potentially unsustainable, activities. Another point of contention is that of the working conditions within the sharing economy that overlap with the gig economy [6]. In America, Great Britain, and Germany, for example, more people in the gig economy have begun to demand guaranteed working hours, more security, and proper employment [7]. In Sweden, the non-profit organization GigWatch criticizes the kind of precarious self-employment offered by some sharing economy companies. At the same time, this new phenomenon also allows students or the unemployed to make some extra money on low-skilled work. Around the world, it is debated whether the sharing economy does any good [8], what kind of effects it has, and how and if it should be promoted.

In another paper in this issue, we investigated how Swedish and Japanese researchers understand the sharing economy and its potential positive and negative effects [9]. Our motivation for studying this ICT (Information Communication Technology) supported phenomenon in these two regional contexts has already been presented elsewhere [10]. In the aforementioned paper [9], we emphasize that while researchers in the two regions often draw on similar definitions and use similar references when studying the sharing economy, the methodological approaches and underlying assumptions used to understand the sharing economy differ greatly. Similar to the circular economy [11], the sharing economy can be described as a floating signifier, which means that it is a contested concept that can be used to promote various and sometimes contradictory ideas.

In this paper, we shift our focus from researchers to politicians and policymakers. Methodologically, we draw on a synthesis of two archival studies of government

\footnotetext{
1 https://www.zipcar.com/

2 https://www.sunfleet.com/

3 https://www.facebook.com/groups/skjutsgruppen/
} 
white papers, articles, reports, motions to the parliament, governmental inquiries, and more. There are substantial differences in the ways the Japanese and Swedish governments operate, and while these differences certainly influence how the sharing economy is framed in the two contexts, we do not delve deep in these differences in this paper. Rather, we aimed to answer how the concept of the sharing economy is understood and approached in these two regional contexts as opposed to why there are similarities and/or differences.

In two previous papers, one by Majima et al. [12] and one by Fors and Lennerfors [13], the authors examined a similar trend in Sweden and Japan: that of Green IT. One conclusion that could be drawn from these two studies is that while Green IT was a popular buzzword in both countries, the values mediated by the concept differed, as did the set of actors promoting it, leading to very different implementations and interpretation processes. While here we are less concerned with theory in this paper than we were in these earlier papers, we show that there are similarities between Green IT and the sharing economy with regard to how the concept is understood and promoted in the contexts of Japan and Sweden.

\section{Methodology}

Archival studies, or archival research methods, encompass numerous research approaches that are aimed at investigating different types of documents produced by organizations (e.g. companies, governments, and NGOs). These documents can be either digital or physical and can include emails, reports, posts on websites and social media, and more. While archival research methods have traditionally been used by historians to "get the facts straight", these methods have recently proven to be useful in other fields of research-not only to uncover "facts" about different organizations but, more importantly, to understand more fully their practices, ideologies, social arrangements, understandings, and assumptions. As suggested by Mohr and Ventresca [14], organizations are fundamentally systems of "talk", and some of this talk is embodied or materialized in various forms of documents. This makes documentation an appealing source of data, "enab[ling] researchers to view the ebb and flow of organizational life, the interpretations, the assumptions, the actions taken and deferred from a range of differing points of view as events unfold across organizational space and time" [14]. In a sense, documentation produced by organizations represents their different forms of social discourse or understanding of phenomena.

In this paper, we used archival studies to investigate how the concept of the sharing economy is understood and promoted in the policies and politics of Japan and Sweden. We examined government white papers, articles, budget propositions, motions to the government, and website posts from the homepages of each government. We conducted two separate archival studies, given that the two political contexts are quite different in how they are organized. Also, the availability of different types of documents proved to be very different. For the Japanese context, the studied documents are mainly official reports and other types of documents from the government while for the Swedish context we were able to get more detailed information 
about the different parties' opinions and understandings of the concept. Thus, there is a difference between the two archival studies concerning their level of abstraction. We will briefly discuss potential limitations of this fact in the concluding discussion of this paper. Despite this, in a synthesis of the studies, we have been able to drawn conclusions about how the sharing economy is understood in the two countries on a general level, how it is promoted, and what kind of underlying values are mediated by the concept and by different political actors.

We qualitatively reviewed 59 individual Japanese documents, including government white papers, research reports, meeting protocols, and policy documents promoting the sharing economy. Data collection was carried out digitally using the keyword “シェアリングエコミー” (sharing economy) in different governmental databases. ${ }^{4}$ We reviewed 39 individual Swedish documents, including government inquiries, meeting protocols, motions to the government, budget propositions, and more. Data collection was performed digitally in the government database using the keyword "delningsekonomi" (sharing economy). ${ }^{5}$

In the following two sections, we present the results of the two archival studies, focusing first on Japan, then on Sweden. As previously mentioned, these contexts are radically different and, while we do not delve into their differences in detail, they are expressed in how the findings are presented. Following these two sections is a discussion, where the results of the two archival studies are synthesised and the similarities and differences concerning the sharing economy in the two contexts are discussed.

\section{The Sharing Economy in Japanese Politics and Policy}

\subsection{Overview of the Sharing economy in Japanese Politics and Policy}

In a report by the Cabinet Secretariat, IT General Strategy Office, in March 2019, the sharing economy is defined as an "economy-vitalizing activity that enables utilization of individuals' and others' usable resources (including nonmaterial ones such as skills or time) by other individuals and others through online matching platforms". Since the concept was first introduced in Japan, different policy documents have been produced and new governmental organizations and NGOs have been formed. We can find the word "sharing economy" in government reports as early as March 2015. ${ }^{6}$ In 2016, the Cabinet Secretariat, IT General Strategy Office, held seven meetings to examine the sharing economy. Consequently, in January of 2017, the Office for Support of the Sharing Economy (シェアリングエコミー促進室) was established in the Cabinet Secretariat, IT General Strategy Office. Its roles are:

\footnotetext{
${ }^{4}$ https://www.e-gov.go.jp/publication/white_papers.html, https://www.e-stat.go.jp, https://kanpou.npb. go.jp, https://www.gov-online.go.jp/topics/link/index.html..

5 https://www.riksdagen.se/en/documents-and-laws/..

6 https://www.soumu.go.jp/johotsusintokei/linkdata/h27_06_houkoku.pdf..
} 
- Besides functioning as an information provider and consultation desk, to spread and promote voluntary roles and communication with related government departments, in addition to the introduction of "best practices", and to advance other activities related to the support of the sharing economy.

- To assess progress once a year to reconsider policies, including model guidelines and to facilitate development. ${ }^{7}$

As a consultation desk, the office responded to 315 inquiries as of the end of March 2019. ${ }^{8}$ It created Share Nippon 100, a list of best practices of local government and private sectors using the sharing economy to solve social problems or vitalize the economy. The office appoints 11 "sharing economy evangelists" who have extensive knowledge of, and experience in, the sharing economy. They are intended to be mediators among stakeholders and to promote the sharing economy as a means of solving local problems.

The Ministry of Public Management actively supports local governments that utilize the potential of the sharing economy to solve local problems. In 2018, its target areas were: (1) the utilization of local human resources, (2) support of "women's activities", such as childcare, (3) insurance of local transport, and (4) the utilization of unused or under-used spaces. The ministry identified 14 local governments engaged in model projects. ${ }^{9}$ The sharing economy is also included as a model of public and private partnership services in the government project "Implementation of Local IoT Support” (地域IoT実装推進事業). Some local public bodies use the sharing economy to utilize the "countryside revitalization support grant system (地 方創生推進交付金制度)”. In January 2019-in response to Japan's proposal for a project under the Ministry of Economy, Trade and Industry-the International Organization for Standardization (ISO) approved the establishment of a committee for the development of international standards for the sharing economy. In response to the issues in promoting home-sharing services, the Japanese government established legal and socio-economic policies. For example, legal regulation of home sharing (“民泊 minpaku”) promulgated in 2018 (Japan Tourism Agency; Ministry of Land, Infrastructure, Transport, and Tourism, 2018) sought to establish safe and secure home sharing during the Tokyo Olympics of 2020.

The sharing economy is also interpreted in the context of "Digital Transformation" in a 2018 Ministry of Public Management report. ${ }^{10}$ In an article in the Financial Times in September 2018, Prime Minister Abe Shinzo said: "Investing in energy transition and the sharing economy will ensure economic growth and dramatically reduce greenhouse gases." 11

It is evident that the Japanese government has actively promoted the sharing economy, both nationally and internationally, since the concept was first introduced

\footnotetext{
7 https://cio.go.jp/share-eco-center.

8 https://www.kantei.go.jp/jp/singi/it2/senmon_bunka/shiearingu/dai2ji-houkokusho.pdf.

9 https://www.kantei.go.jp/jp/singi/it2/senmon_bunka/shiearingu/dai2ji-houkokusho.pdf.

10 http://www.soumu.go.jp/johotsusintokei/whitepaper/ja/h30/html/nd102200.html.

11 https://www.ft.com/content/c97b1458-ba5e-11e8-8dfd-2f1cbc7ee27c.
} 
in Japan. New organizations and projects have developed to promote the concept with businesses. In the following section, we focus on what benefits the Japanese government and governmental organizations expect from the sharing economy.

\subsection{Estimated Effects of the Sharing Economy in Japan}

As demonstrated by the words of the Prime Minister at the beginning of Sect. 3, the Japanese government is actively promoting the sharing economy since it is assumed to provide economic, social, and environmental benefits. From policy documents, however, it is clear that economic growth is the government's first concern, followed by social sustainability. A term symbolising both economic and social effects, “Dynamic Engagement of All Citizens” (一億総活躍社会), was coined as part of a solution to declining birth rates and an aging population, a structural problem for Japan. It aims to promote ${ }^{12}$ :

- An inclusive society where everyone-youngsters and older adults, women and men, people with deficiencies or intractable diseases, and those who have experienced failure — can play an active part.

- A society in which personality and diversity are respected, everyone can realize the fruits of their efforts and show their abilities, and everyone feels worthy of living at home, in local communities, and at places of work.

- A new economic and social system that produces "positive feedback of growth and distribution", and where activities designed to grow the economy strengthen the basis of childcare support and social welfare, resulting in further economic stabilization and prosperity.

In 2015, Prime Minister Abe stated that Japan would promote Dynamic Engagement of All Citizens by mobilizing different sharing economy actors. According to the report of the Office for Support of the Sharing Economy:

"[The] sharing economy stimulates the marketization of unutilized capital and individual potential. It is expected to contribute to the realization of the Dynamic Engagement of All Citizens through growth in individual income as a result of the vitalization of various services provided by individuals. Also, along with the spread of the sharing economy, there is a possibility that it will lead to a national work style reformation (働き方改革), such as a reconsideration of rules that currently ban workers' side businesses."13

According to its 2016 report, the Office expects the sharing economy to promote:

- New experiences and contribute to economic growth

- Efficient utilization of sources

- Countryside revitalization, co-assistance among citizens

\footnotetext{
12 https://www.kantei.go.jp/jp/headline/ichiokusoukatsuyaku/index.html.

13 http://www.kantei.go.jp/jp/singi/it2/senmon_bunka/shiearingu/chuukanhoukokusho.pdf.
} 
- Production of innovation

- Sustainable development of our country that harmonizes with the international movement.

In its 2019 report, new income for the government, development of new tourist resources, and new opportunities for athletes were added (suggested by Japan Sports Agency).

In a white paper called "Information and Communications in Japan" from 2018, the Ministry of Public Management mentions estimated economic effects, such as the expansion of consumption by solving supply shortages and actualizing potential demands, and the expansion of associated businesses. ${ }^{14}$ In the report "Research on the Realization of Inclusion by ICT" from the same year, the ministry asserts that the sharing economy can contribute to a “work style reformation” (動き方改革) through the promotion of telework and the "formation of social bonds", understood as social inclusion. ${ }^{15}$

In a 2018 white paper titled "Annual Report on the Environment, the Sound Material-Cycle Society and Biodiversity in Japan", the Ministry of Environment discussed ecological, economic, and social effects of the sharing economy. ${ }^{16}$ Ecological effects included the possibility of providing new lifestyles that can replace excessive consumption and the use-and-dispose culture, reductions in $\mathrm{CO}_{2}$ emissions and the use of resources, and a reduction in the use of air conditioners through space sharing. Economic effects included an enriched consumer life, elevation of the production value of the entire social economy (i.e. utilization of unemployed capital), utilizing data analysis, reduction of expenses through ride sharing, and the provision of "income for providers, and reduction of expenses on the part of users". Identified social effects included progress through regional development, health promotion, transportation for the elderly through ride sharing, and renewed social bonds resulting from space sharing.

Interestingly, the Japan Sports Agency, an external bureau of the Ministry of Education, has also analysed the social and economic effects of the sharing economy. In the "Research Report for Introduction of the Sharing Economy of Sports Coaching Skill and Space," the agency points out that the sharing economy increases opportunities for coaches and their incomes, as well improvement of the participation rate in sports for those in their $20 \mathrm{~s}$ and $30 \mathrm{~s}$ (the generation expected to further increase their participation rate in sport, and the core users of the sharing economy in Japan), in addition to opening possibilities for data collection at sports facilities (including data on their deterioration) and improving the operation of facilities resulting from the sustainable promotion of sports, including reductions in public expenditures.

\footnotetext{
${ }^{14}$ http://www.soumu.go.jp/johotsusintokei/whitepaper/ja/h30/pdf/index.html. http://www.soumu.go.jp/johotsusintokei/whitepaper/eng/WP2018/2018-index.html.

15 http://www.soumu.go.jp/johotsusintokei/linkdata/h30_03_houkoku.pdf.

16 http://www.env.go.jp/policy/hakusyo/h30/html/hj18010303.html. http://www.env.go.jp/en/wpaper/2018/index.html.
} 
While these reports indicate that the Japanese government has a positive attitude toward the sharing economy, other parts of the government have expressed concerns about its risks and negative impacts. The Office of Support for the Sharing Economy says that the sharing economy may pose a safety risk since responsibility is not associated with a company. ${ }^{17}$ The Ministry of Public Management mentions negative effects on the existing market. ${ }^{18}$ The Ministry of the Environment notes a possibility of excessive dependence on the limited number of drivers, the mental strain on drivers given their liability in the event of an accident, and a lack of understanding about ride sharing. ${ }^{19}$ The Japanese Communist Party has criticized the Japanese government for its promotion of the sharing economy, particularly ride sharing, saying that it poses an increased risk to users since drivers are not required to have special licences and do not have stable employment contracts. ${ }^{20}$ Apparently, these criticisms have had little impact on current policies.

\section{The Sharing Economy in Swedish Politics and Policy}

\subsection{An Overview of the Sharing Economy in Swedish Politics and Policy}

The sharing economy has been discussed in Swedish politics and policy since at least 2015. The sharing economy is generally promoted as inherently positive, as it has the potential to benefit society, the economy, and the environment. The concept is rarely clearly defined-often it is discussed on a general level. The most commonly mentioned actors in the sharing economy by politicians are Uber and Airbnb, with home and car sharing receiving the most attention. Generally, the sharing economy is used as an umbrella term for activities aimed at reducing resource consumption through more effective use of products and services. ${ }^{21}$ Examples include digital services that offer car and tool pools.

According to the Swedish digital policy, Sweden aims to become the best country in the world to reap the benefits of digitalization, and the sharing economy is one way to achieve this. There is a general consensus among the political campsliberal, social democrat, socialist, and conservative - that the sharing economy and different kinds of sharing practices should be promoted. However, while politicians are generally sympathetic toward the sharing economy, there are differences among the parties in the ways they discuss it and seek to promote it in practice. There are also discrepancies between the perceived risks and rebound effects of the sharing economy from the perspectives of the various parties.

\footnotetext{
17 http://www.kantei.go.jp/jp/singi/it2/senmon_bunka/shiearingu/chuukanhoukokusho.pdf.

18 http://www.soumu.go.jp/johotsusintokei/whitepaper/ja/h30/pdf/index.html. http://www.soumu.go.jp/johotsusintokei/whitepaper/eng/WP2018/2018-index.html.

19 http://www.env.go.jp/policy/hakusyo/h30/html/hj18010303.html http://www.env.go.jp/en/wpaper/2018/index.html.

${ }^{20}$ https://www.jcp.or.jp/akahata/aik18/2018-05-19/2018051904_03_1.html, http://workers.jcp-kanag awa.jp/archives/15696.

${ }^{21}$ https://data.riksdagen.se/fil/E4D95A87-F088-484B-96DD-60603BE601BF.
} 
The Moderate Party, one of the conservative parties in Sweden, states that Sweden should be"the best country in the world for sharing goods and services". ${ }^{22}$ It sees how the sharing economy can create a foundation for new innovation and increased growth, ${ }^{23}$ promote more efficient use of resources, and lead to both environmental and personal financial benefits. The Moderate Party further emphasizes that the sharing economy challenges the traditional view of how the economy works and, more importantly, the employer-employee relationship. This, they argue, means the Swedish government needs to change regulations to support the sharing economy, ${ }^{24}$ not least of which is the system of taxation. According to The Moderate Party, the current system cannot accommodate the sharing economy because it is too complicated for users and product providers and platforms. They suggest tax cuts for users and providers to promote the development of the sharing economy and reduce problems with tax evasion. ${ }^{25}$ They argue that current regulations can be an obstacle to innovation and new technologies that may emerge out of the sharing economy. Similar arguments have been brought forward by The Liberals: "when it comes to ... models for sharing services, today's regulation stands in the way of the growth of these services." 26

Politicians on the left of the political spectrum express mainly positive views of the sharing economy. The Left Party argues that the sharing economy could prevent overconsumption of goods, ${ }^{27}$ which is good for the environment. ${ }^{2829}$ This position is shared by The Swedish Green Party, which also argues that the sharing economy can help reduce unemployment and create economic growth. ${ }^{30}$ According to The Left Party, platform providers have a major responsibility to provide information about tax rules to service users and those who provide the actual products and services (i.e. the platform workers). They also seems to view the sharing economy as a way of stimulating a more circular economy. ${ }^{31}$

\subsection{Estimated Effects and How the Sharing Economy Should be Promoted}

There are differences among the parties in Sweden as to how the sharing economy should be promoted. Anette Akesson, a member of The Moderate Party, suggests that the use of sharing services could be made cheaper by reducing taxes on them. She proposes that RUT and ROT (tax deduction for renovation, home cleaning, etc.) should include sharing (RÄT, as in "rättvist", "fair"). ${ }^{32}$ The nationalist party The

\footnotetext{
22 https://data.riksdagen.se/fil/771FE15B-82B9-437E-8BAF-F94832DAFCF7.

${ }^{23} \mathrm{https} / / /$ data.riksdagen.se/fil/DFA066C9-7B04-4616-94E0-A6AEE8C83781.

$24 \mathrm{https} / / /$ data.riksdagen.se/fil/C7733570-CA00-4E5C-995E-8B259B0062CF.

$25 \mathrm{https} / / /$ data.riksdagen.se/fil/2EEBD657-21E9-434E-B1FD-03CF5DF22979.

${ }^{26} \mathrm{https} / / /$ data.riksdagen.se/fil/594083AB-DD4B-44E2-A9D5-96FB2ACC434E.

${ }^{27}$ https://data.riksdagen.se/fil/08299248-CC51-4733-BCCA-C9FD0217BA4C.

${ }^{28}$ https://data.riksdagen.se/fil/9030DEBF-E1FB-44EA-8A06-0EEE3546EE5F.

${ }^{29}$ https://data.riksdagen.se/fil/735B48B7-4167-40B7-9AEF-751A59A50AD1.

${ }^{30} \mathrm{https} / / /$ omniekonomi.se/bolund-rasar-mot-konsumtion-cirkular-ekonomi-som-galler/a/70xLr9.

${ }^{31} \mathrm{https}: / /$ data.riksdagen.se/fil/735B48B7-4167-40B7-9AEF-751A59A50AD1.

${ }^{32}$ https://data.riksdagen.se/fil/26E207A8-D9F8-4DAD-8E3C-45B7FEAF9E94.
} 
Sweden Democrats argue for tax cuts to promote and simplify the use of sharing economy services. ${ }^{33}$

Rather than tax cuts, The Left Party propose forming an association that could provide information, pursue the question of working conditions, compare different rating systems, and assess the quality of sharing economy platforms. The Social Democrats promote increased awareness and information dissemination about the sharing economy and making sharing a safe experience through clearer roles and responsibilities. They also argue that sharing economy regulations need to be stricter to protect both consumers and providers.

All Swedish political parties agree that the sharing economy poses one major risk, which is that workers in the sharing economy may fail to properly declare and pay taxes. It has been estimated that the majority of people working in the sharing economy either do not report income at all or make mistakes when declaring income. Other risks are emphasized by different political parties. Jessica Rosencrantz of The Moderate Party, one of the main proponents of the sharing economy in Swedish politics, sees three primary risks. First, she thinks the sharing economy will have radical and lasting impacts on how the labour market is organized. Second, she thinks it is unclear how risks and responsibilities should be divided among actors within the sharing economy. Third is the issue of cybersecurity since the sharing economy is largely mediated by digital platforms where user and provider data are stored. Another risk highlighted by The Moderate Party is that activities within the sharing economy today do not count toward GDP growth. If more people start shifting from traditional consumption to sharing platforms, new ways of calculating GDP would have to be developed.

The Left Party sees additional risks with the sharing economy. Highlighting one of its most important rebound effects [15], they argue it is important not to forget that public transportation is the most sustainable mode of travel and that mobility services should be seen not as a substitute for public transportation but as a substitute for owning a car. ${ }^{34}$ Another risk frequently highlighted by the Left is that the sharing economy is not compatible with the Nordic Model. ${ }^{35,36}$ While this is also highlighted by the political Right, the Left wants to adjust the sharing economy to work within the Nordic Model, whereas the Right advocates for adjusting the Nordic Model to fit within the new labour conditions of the sharing economy. ${ }^{37,38}$

In 2016, the Swedish government set up a special inquiry into the different models and platforms that facilitate sharing practices among private persons in Sweden. By far the most ambitious initiative since the sharing economy concept first emerged in 2015, the aim of the inquiry was to analyse the role of users and actors, and their

\footnotetext{
33 https://data.riksdagen.se/fil/7ED1FBBA-2BFC-4BA0-9942-C64D9C0108DA.

34 https://data.riksdagen.se/fil/E4DDD20F-A30C-4163-87DE-46E8CB1CEC4A.

35 https://arbetet.se/2016/10/03/har-tavlar-arbete-och-kapital/.

36 The Nordic Model means that the conditions of the labour market are decided in dialogue between labour unions and employers. Problems arise when traditional roles such as employees and employers are unclear, which is sometimes the case for people working in the sharing economy.

37 https://data.riksdagen.se/fil/C7733570-CA00-4E5C-995E-8B259B0062CF.

38 https://www.riksdagen.se/sv/dokument-lagar/dokument/motion/mojligheternas-land_H7023108/html.
} 
legal positions, to determine whether regulations should be adjusted to catch up with rapid developments within the field. A special report was released in 2017 called Sharing Economy-On the Terms of the Users. As the name implies, the focus was on how to provide good, safe experiences for users of sharing services, with an overview of the sharing economy in Sweden and suggestions for future action. The report concluded that, while existing regulations are in fact not appropriate, there is not enough support to change them as few people are actually engaged in the sharing economy on a daily basis. The report proposed that the Swedish Consumer Agency needs to follow the sharing economy more closely and report on its development to the government. The Swedish Consumer Agency should also be tasked with "providing information about what sharing economy transactions imply, the risks and opportunities, as well as giving individual guidance to users in conjunction with such transactions." 39 This task was given to The Swedish Consumer Agency in 2018.

The expected outcome of these slight policy changes is that more people-not just those with "idealistic and social motives" 40 — will participate in the sharing economy because of the benefits of sharing compared to consuming new products. The inquiry expects growth to occur mostly in the areas of car and home sharing given their significant economic benefits as compared to, for example, sharing tools or clothes. The inquiry extends its focus beyond users and providers by acknowledging, to a lesser extent, the sustainability potential of the sharing economy. It states that local initiatives are often in need of financial support but that private investors, foundations, crowdfunders, etc., can already provide this support. It emphasizes the role of, for example, Tillväxtverket (Swedish Agency for Economic and Regional Growth) and Vinnova (Sweden's innovation agency) in promoting and funding sharing economy initiatives. The report suggests that these agencies and organizations could be given the responsibility to create funding and development programs for sharing economy initiatives in the future. While the report has a positive view of the sustainability potential of the sharing economy, it also emphasizes that certain sharing practices can have rebound effects that offset positive environmental effects.

In conclusion, political parties and actors across the political spectrum in Sweden are promoting the sharing economy. Despite proposals for initiatives and policy changes to further promote it, few concrete changes have materialized.

\section{Concluding Discussion}

In another paper published in this special issue [9], we investigated research on the concept of the sharing economy in Japan and Sweden through a synthesis of two systematic literature reviews in each country. Despite some similarities between the two countries, we found substantial differences in the ways the sharing economy was understood and approached methodologically by researchers. While we concluded

39 https://data.riksdagen.se/fil/E4D95A87-F088-484B-96DD-60603BE601BF, p. 30.

40 https://data.riksdagen.se/fil/E4D95A87-F088-484B-96DD-60603BE601BF, p. 300. 
that most researchers in both contexts show optimism toward the concept and aim to promote it normatively, they emphasize different impacts and risks. In general, Japanese researchers focus on the economic effects of the sharing economy, while Swedish researchers tend to emphasize its potential to bring social and environmental value. We emphasized that Japanese research is characterized by consensus while Swedish research is characterized by presenting conflicting understandings of the sharing economy. We have shown in this paper that similar tendencies exist when examining the sharing economy in a political and policy context.

In this second of the two studies on the meaning of the sharing economy in Japan and Sweden respectively, we have in a synthesis of two separate archival studies focused on the political spheres. We have examined government white papers, articles, budget propositions, motions to the government, and website posts from the homepages of each government. We observed that while there are similarities on a general level-for example, that similar definitions of the sharing economy are used-assumptions about, and perceived positive and negative effects of, the sharing economy differ greatly between the political and policy contexts of the two countries.

In Sweden, the sharing economy has been discussed politically for about as long as it has in Japan. While different political parties highlight its different positive and negative effects, all parties show optimism toward the sharing economy regardless of underlying political ideologies. But it is clear that different political parties and even individuals have different understandings of what the concept means. Most politicians more or less agree that the sharing economy can provide working opportunities, economic growth, innovation, and social and environmental benefits, but there are major differences of opinion in how to promote the sharing economy and create a safe and positive experience for users and providers alike. While the political Right promotes tax cuts and deregulation (to promote participation, prevent tax evasion, and provide a safe and positive sharing experience), the political Left tends to propose more strict regulation when it comes to responsibilities and roles in the sharing economy (particularly tax responsibilities). The political left also emphasizes how working conditions in the sharing economy can be reconciled with the Nordic Model. The political right, on the other hand, is keen to promote the sharing economy but lacks clear suggestions on how to solve this problem and what kind of sharing should be promoted and why.

While similar observations have been made in our first paper in this special issue [9], such tendencies are even more evident among Swedish politicians and policymakers. The sharing economy is not "one thing", but a contested concept open to many different interpretations (i.e. a floating signifier or, as expressed in Majima et al. [9], a "Rashomon-like" reality). This means that, although all political parties in Sweden promote the sharing economy, they promote very different ideas or visions of it in practice. Such ideas range from reduced consumption of goods (i.e. improved environmental sustainability), better private finances, more unqualified or precarious jobs, to lower taxes and increased economic growth. It is clear that political parties express different ideas in line with their own ideologies despite promoting the very same concept on the surface. The Swedish political debate is heavily 
influenced by the assumption that the sharing economy has positive effects on environmental sustainability.

In Japan, on the other hand, the sharing economy is mainly recognized as a new way to promote economic activity, not least to solve certain problems that are to some extent unique to Japan. In practice, it is seen as a new business model that can be implemented by companies to make better use of existing, underutilized resources. As to be expected from such a perspective, economic growth is the main driver for implementing sharing practices. Other positive effects that appear unique to, or at least heavily emphasized in, Japan compared to other countries, are the inclusion of different social groups, countryside revitalization, and public transportation. Problems specific to Japan, namely depopulation and an aging citizenry, are expected to be alleviated by sharing practices. Compared to Sweden, where the sharing economy acts as a floating signifier, open for interpretation by actors with different motives and worldviews, there seems to be a consensus in Japan about what the sharing economy is, what effects it will have, and how it can be promoted. Although the term arrived simultaneously in Japan and Sweden, it was translated into Japan faster than it was translated in Sweden, where many conflicting perspectives are still present. Powerful actors in Japan, such as the Cabinet Secretariat, the IT General Strategy Office, and the Sharing Economy Association, facilitated this translation process. However, it is unclear whether the shared understanding among politicians and policymakers in Japan is a result of actual consensus, or a lack of indepth critical discussions and debates about the sharing economy within the political sphere, including what it is, what its effects are, and the power and influence of the actors who have promoted and interpreted the concept.

Differences in how the sharing economy is understood in Japan and Sweden have had important consequences for how it has been promoted in the policy. On the one hand, Japanese policymakers are already promoting the sharing economy, as it was translated and assimilated into the Japanese context relatively quickly. Compared to Sweden, where many proponents of the sharing economy argue that its development has been rather slow, Japan has come a long way in promoting certain sharing practices. Given that the concept is still ambiguous and contested in Sweden, political parties have yet to agree on how to promote it and avoid any potential negative consequences. In practice, Sweden has made little progress relative to Japan when it comes to implementing new policies, laws, or regulations. On the other hand, that the concept is still open for interpretation in Sweden means that there are opportunities to reach a deeper understanding of how the sharing economy can help to promote a more sustainable society. While the concept, as it is understood in Japan, certainly has positive implications for environmental sustainability, it is unlikely that such a narrow understanding of the sharing economy can promote "a new kind of capitalism" [16] that can reshape the current unsustainable business landscape [17].

There are some limitations to the study. It has to be emphasized yet again that these two political contexts are very different, and while we have not delved into these differences to any great detail in this paper, it is clear that these differences prevent a direct and detailed comparison between the two contexts. While there are many differences between the political contexts, reflected for example in The Economist's Democracy Index [18], the difference that could have had direct impact on the credibility of the 
study is the availability of documents for the archival studies. In Sweden, more political documents are publicly available than in Japan, meaning that the level of analysis is different between the two archival studies. Therefore, while we have been able to give detailed accounts of the different parties' view of the sharing economy in Sweden, the findings in Japan are more general, although some comparisons between different parties' views have been made. This could have affected the findings of the study. Although the study clearly shows that there is more consensus in the Japanese context than in the Swedish context about the understandings and assumptions about the sharing economy, this limitation could mean that this finding of the study is to some extent exaggerated.

Acknowledgements This study was funded in part by the JSPS/STINT Bilateral Joint Research Project "Information and Communication Technology for Sustainability and Ethics: Cross-national Studies between Japan and Sweden" (JPJSBP120185411).

Funding Open access funding provided by Uppsala University.

Open Access This article is licensed under a Creative Commons Attribution 4.0 International License, which permits use, sharing, adaptation, distribution and reproduction in any medium or format, as long as you give appropriate credit to the original author(s) and the source, provide a link to the Creative Commons licence, and indicate if changes were made. The images or other third party material in this article are included in the article's Creative Commons licence, unless indicated otherwise in a credit line to the material. If material is not included in the article's Creative Commons licence and your intended use is not permitted by statutory regulation or exceeds the permitted use, you will need to obtain permission directly from the copyright holder. To view a copy of this licence, visit http://creativecommons.org/licen ses/by/4.0/.

\section{References}

1. Botsman, R., \& Rogers, R. (2010). What's mine is yours: the rise of collaborative consumption. New York: HarperCollins Publishers.

2. Kumar, V., Lahiri, A., \& Dogan, O. B. (2018). A strategic framework for a profitable business model in the sharing economy. Industrial Marketing Management, 69, 147-160.

3. Guyader, H. (2019).The Heart and Wallet Paradox of Collaborative Consumption. Doctoral thesis. Linköping University Electronic Press.

4. Sung, E., Kim, H., \& Lee, D. (2018). Why do people consume and provide sharing economy accommodation? A sustainability perspective. Sustainability, 10, 2072.

5. Lahti, V-M., Selosmaa, J. (2013). A fair share: Towards a new collaborative economy. Atena Kustannus Oy.

6. De Stefano, V. (2015). The rise of the just-in-time workforce: On-demand work, crowdwork, and labor protection in the gig-economy. Comparative Labor Law \& Policy Journal, 37, 471.

7. GigWatch-About us, https://www.gigwatch.se/en/about-us/.

8. Dillahunt, T.R., Lampinen, A., O’Neill, J., Terveen, L., Kendrick, C. (2016). Does the Sharing Economy do any Good? In: CSCW'16 Companion. February 27-March 2, San Francisco, USA.

9. Majima, T., Fors, P., Inutsuka, Y., Orito, Y. (2021). Is the meaning of the sharing economy shared among us? Comparing Japanese and Swedish researchers' perspectives. Review of Socionetwork Strategies, $1-20$.

10. Murata, K., Lennerfors, T.T. (2021). Introduction to special issue on ICT for Sustainability and Ethics: Cross-national Studies between Japan and Sweden. Review of Socionetwork Strategies, Forthcoming.

11. Corvellec, H., Böhm, S., Stowell, A., \& Valenzuela, F. (2020). Introduction to the special issue on the contested realities of the circular economy. Culture and Organization, 26(2), 97-102.

12. Majima, T., Udagawa, M., Yotsumoto, M., \& Lennerfors, T. (2017). Green IT did not take place: The translation of environmentally friendly IT in Japan. Journal of Information and Management, 37(2), 81-96. 
13. Fors, P., Lennerfors, T.T. (2013). Translating Green IT: the case of the Swedish Green IT Audit. Proceedings of the First International Conference on Information and Communication Technologies for Sustainability, 208-216.

14. Ventresca, M.J., Mohr, J.W. (2017). Archival research methods. Blackwell companion to Organ. $805-828$.

15. Börjesson Rivera, M., Håkansson, C., Svenfelt, Å., Finnveden, G. (2014). Including second order effects in environmental assessments of ICT, Environmental Modelling \& Software, 56, 105-115.

16. Alden, W. (2014). The Business Tycoons of Airbnb. The New York Times Magazine. https://www.nytim es.com/2014/11/30/magazine/the-business-tycoons-of-airbnb.html. Accessed 12 August 2020.

17. Fors, P., \& Lennerfors, T. T. (2020). The individual-care nexus: A theory of entrepreneurial care for sustainable entrepreneurship. Sustainability, 11(18), 4904.

18. The Economist. (2019). Democracy Index 2019. https://www.eiu.com/public/topical_repor t.aspx?campaignid=democracyindex2019. Accessed 22 December 2020.

Publisher's Note Springer Nature remains neutral with regard to jurisdictional claims in published maps and institutional affiliations.

\section{Authors and Affiliations}

\section{Per Fors $^{1}$ (D) $\cdot$ Yu Inutsuka ${ }^{2} \cdot$ Takashi Majima $^{3} \cdot$ Yohko Orito $^{4}$}

Yu Inutsuka

inutsuka@nitech.ac.jp

Takashi Majima

t-majima@isc.senshu-u.ac.jp

Yohko Orito

orito.yohko.mm@ehime-u.ac.jp

1 Uppsala University, Uppsala, Sweden

2 Nagoya Institute of Technology, Nagoya, Japan

3 Senshu University, Kawasaki, Japan

4 Ehime University, Matsuyama, Japan 